\title{
Neonatal mortality in Sudan: analysis of the Sudan household survey, 2010
}

\author{
Amal O Bashir ${ }^{1}$, Ghada H Ibrahim², Igbal A Bashier ${ }^{1}$ and Ishag Adam ${ }^{3^{*}}$
}

\begin{abstract}
Background: Sudan is classified as having insufficient progress in achieving the Millennium Development Goal (MDG-4), where the levels of child and infant mortality are among the highest in the region and the world. This study investigated factors associated with neonatal mortality in Sudan. Neonatal death is defined as death within the first 28 days of life.

Methods: This study analysed data from the Sudan Household Health Survey 2nd round, which was carried out in 2010. Total of 6,198 live-born infants delivered within the two years preceding the survey were included as the study population. Multivariate logistic regression was used to model neonatal mortality as a function of maternal health parameters, socioeconomic indicators and the sex of the child.

Results: There were 189 neonatal deaths out of 6,198 live births (3.0\%). In the multiple logistic regression, the factors associated with neonatal mortality were advanced maternal age ( $\geq 40$ years; $\mathrm{OR}=2.4 ; 95 \% \mathrm{Cl}: 1.21,4.78$, $\mathrm{p}=0.012)$, poor household wealth index $(\mathrm{OR}=1.6 ; 95 \% \mathrm{Cl}: 1.18,2.47, \mathrm{p}=0.005)$, male child $(\mathrm{OR}=1.8 ; 95 \% \mathrm{Cl}$ : 1.31, $2.42, \mathrm{p}<0.001)$, delivery of baby by Caesarean section ( $\mathrm{OR}=1.6 ; 95 \% \mathrm{Cl}: 1.78,2.42, \mathrm{p}=0.013)$ and delivery complications ( $\mathrm{OR}=1.4 ; 95 \% \mathrm{Cl}: 1.18,2.15, \mathrm{p}=0.002)$.

Conclusion: Public health interventions which target neonatal mortality reduction should adopt a risk-factor-based approach to detect pregnancy complications early and once identified, the health system should be strengthened so that these complications can be dealt with adequately.
\end{abstract}

Keywords: Neonatal mortality, Maternal factors, Delivery complications, Sudan

\section{Background}

Globally,7.6 million children die each year from preventable causes, and of these, about $40 \%$ die in the neonatal period [1]. The vast majority of these deaths are in lowand middle-income countries such as Sub-Saharan Africa and most of them occur at home [2,3].

Even though the under-five mortality rate is declining by a rate of $2.9 \%$, the reduction in the neonatal mortality rate of $2.1 \%$ per year lags behind the rate of reduction among older age children $[1,4,5]$. The high rate of the neonatal death is one of the reasons why the Millennium Development Goal (MDG-4) for reducing under-five mortality by two thirds by the year 2015 may not be achieved [6]. Unfortunately, most of the data/interventions to achieve MDG-4 were developed in rich countries where the

\footnotetext{
* Correspondence: ishagadam@hotmail.com

${ }^{3}$ Faculty of Medicine, University of Khartoum, Khartoum, Sudan

Full list of author information is available at the end of the article
}

incidence of under-five mortality is low. Data on the epidemiology of neonatal mortality were scarce in societies with higher neonatal mortalities and there is less access to cost-effective interventions to prevent them - "the inverse information and care law" [7].

Despite the fact that neonatal mortality is responsible for $40 \%$ of all under-five mortality and more than $50 \%$ of total infant mortality, it is not explicitly targeted by MDGs [8]. Addressing neonatal mortality is a major enabler to reduce child mortality and achieve the MDG-4 target [3].

Understanding the factors associated with neonatal mortality is important so that public health intervention efforts to prevent neonatal mortality can be properly focused, based on the evidence [3]. In addition, the availability of valid epidemiological information at the country level will be an important determinant of success in

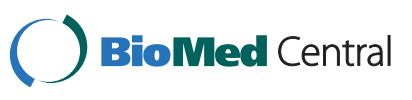


meeting and in measuring progress toward the MDGs for child survival [1].

The causes of neonatal mortality vary between (and within) countries [2,9]. There is a scarcity of information about the direct causes of neonatal deaths in low-income communities; population-based information in these settings is largely dependent on verbal reports of autopsies of variable quality. Global estimates are only possible through statistical modelling [2].

Sudan is classified as having made insufficient progress to achieve MDG-4 [1]. The current infant mortality rate is 60 per 1,000 live births and the under-five mortality rate is 82 deaths per 1,000 live births. The neonatal mortality rate is also high ranging from 34 to 47 per 1,000 births [10].

This aim of this study was to investigate the factors associated with neonatal mortality in Sudan. Such data are of paramount importance, providing the evidence necessary to guide future interventions to reduce the infant death rate.

\section{Methods}

\section{Data sources}

Data collected by the Sudan Household Health Survey 2nd round (SHHS2, 2010), which was carried out in 2010, were used in this study [10]. This survey collected information on children and women, measuring key indicators that allow the country to monitor progress towards MDGs and other internationally agreed upon commitments. Although SHHS2, 2010 covered both Northern and Southern Sudan, only the data covering the 15 Northern States was used in this study (Figure 1). This was due to the Southern States' data being unavailable. In each state, 25 households from each of 40 clusters (villages) were sampled. A two-stage cluster sampling design was employed to choose the samples in each state. Questionnaires were based on the Standard Multiple Indicator Cluster Survey, fourth round (MICS4) and the Pan Arab Project for Family health (PAPFAM) questionnaires [11], which were adapted and amended to suit the country.

For this study, data were obtained from the Women's Questionnaire (for women aged 15-49 years), which included information on demographic characteristics, and then details of births within the 2 years preceding the survey - child mortality, history of antenatal care, delivery assistance, and mode and place of delivery for births.

\section{Conceptual framework}

A previously designed conceptual framework for the study of child survival in developing countries $[3,12]$ was adopted and slightly modified based on the available

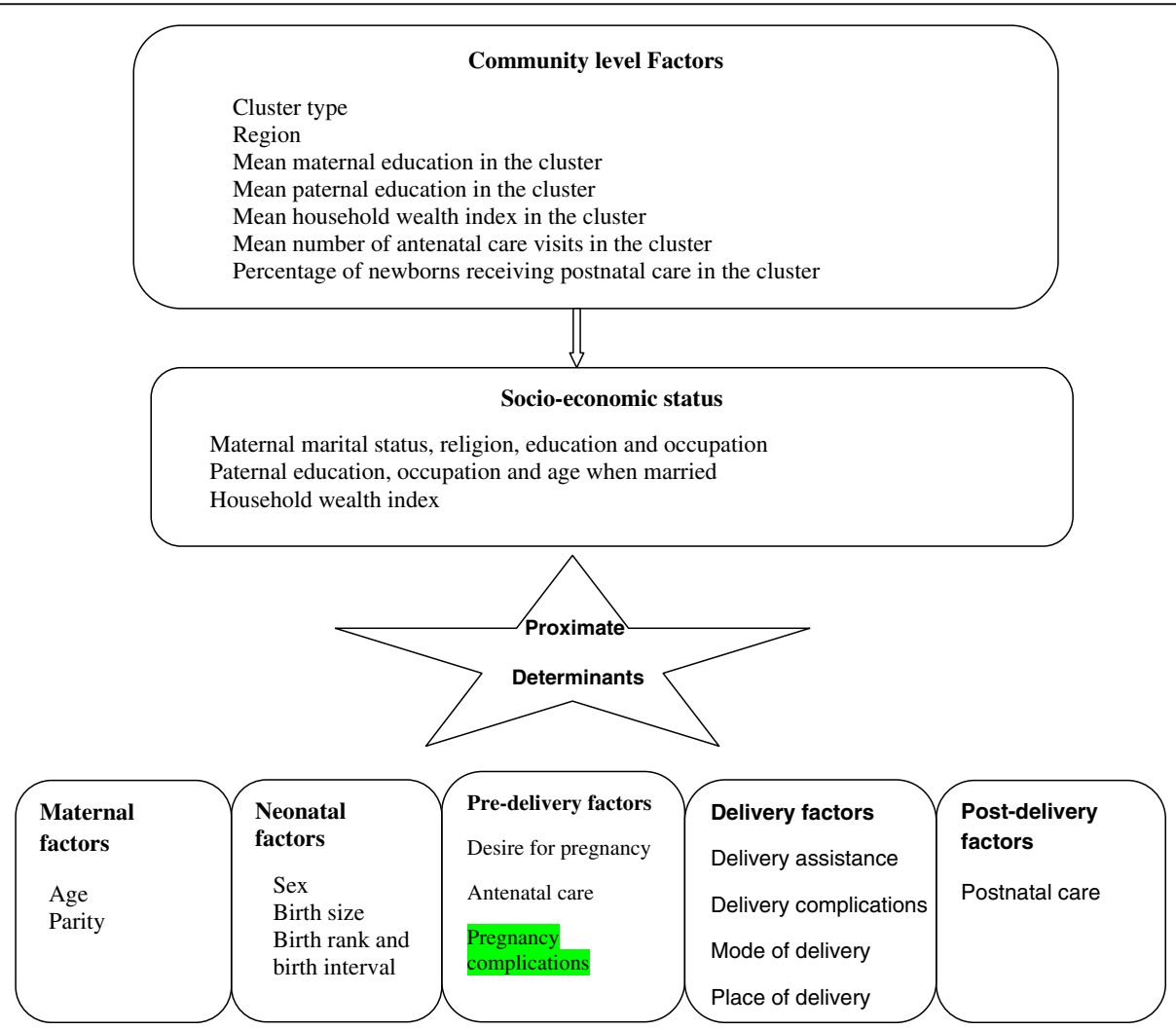

Figure 1 Conceptual framework for factors influencing neonatal mortality. 
data in the SHHS2, 2010, for identifying independent variables (Figure 1). Some factors were not available from the SHHS2, 2010, so they were excluded from the analysis (Figure 2) (e.g. community-level factors and post-delivery factors).

\section{Study population}

Live-born infants delivered within the 2 years preceding the survey (i.e. February 2008 onwards) were included as the study population $(n=6,198)$.

\section{Description of variables}

Table 1 shows a list of all the variables used in this study along with their definitions and categorisations. Neonatal mortality is defined as the death of a child within the first 28 days of their life. It was employed as a binary outcome variable in the analysis.

\section{Demographic and socio, economic variables}

These incorporated sex of child; maternal age in years (<20, 20-29, 30-39, $\geq 40$ yrs); maternal education level (illiterate, intermediate or less ( $\leq 8$ years) and secondary or above ( $>8$ years); head of household education (illiterate, have some education), area of residence (rural, urban); household wealth index (high, middle, low).

\section{Maternal health variables}

The included variables were; parity (primiparae, 2 to 4 children, multiparae 25 ); antenatal care utilization (ANC) (non/receiving traditional health care, and receiving professional health care); delivery assistance was treated in the same way as the ANC variable; mode of delivery (vaginal, Caesarean section); place of delivery (home, health facility deliveries); ever had tetanus toxoid vaccination (yes, no); ever experienced complication during last pregnancy (yes, no); ever experienced complication during last delivery (yes, no).

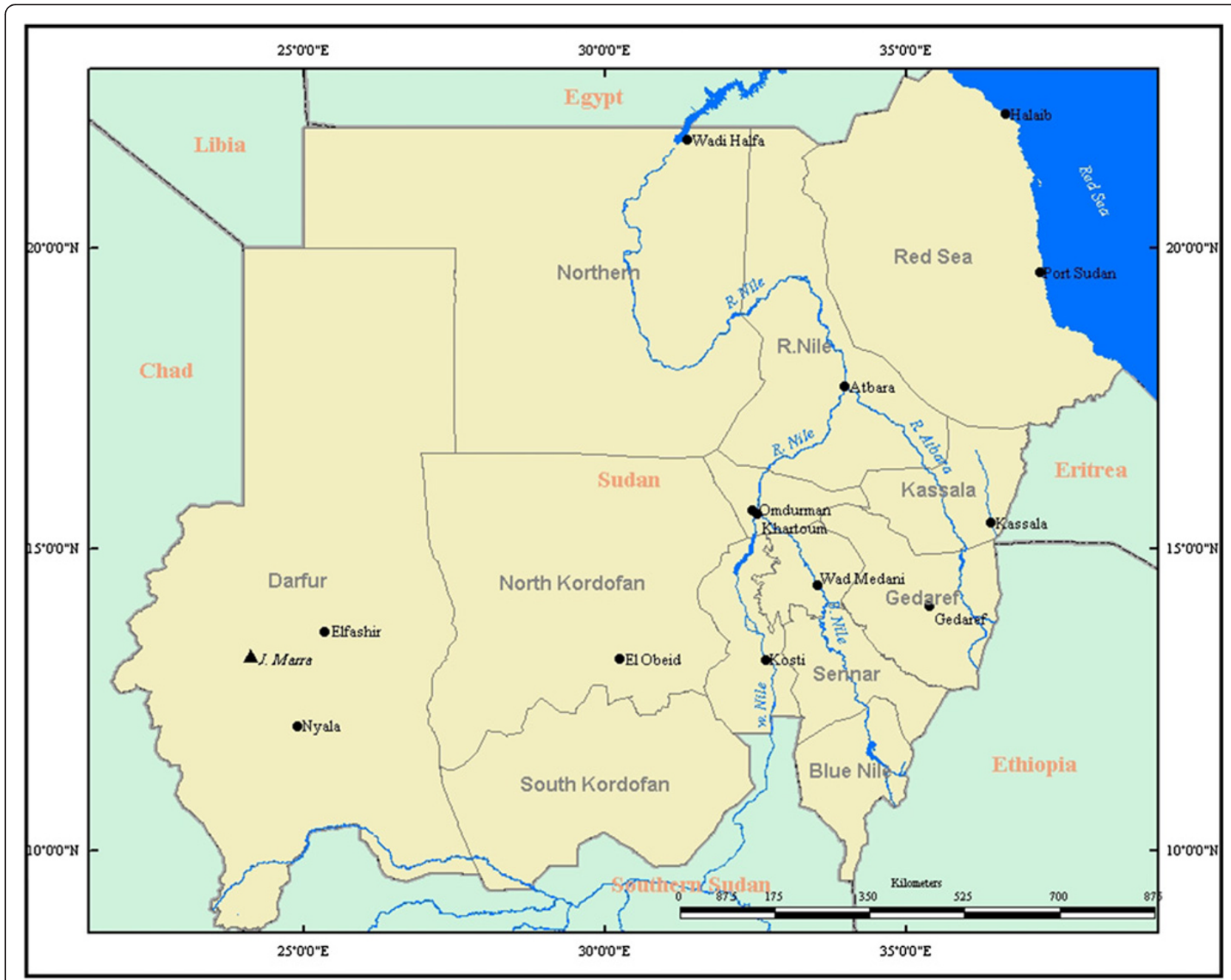

Figure 2 Map of Sudan. 
Table 1 Definition and categories of variables used in the analysis into neonatal mortality rates in Sudan

\begin{tabular}{|c|c|}
\hline Variable & Definition and categories \\
\hline Child sex & Male /female \\
\hline Maternal age in years & $\begin{array}{l}\text { Original variable present the mother's age as continues variable. However, in the analysis mother's age was } \\
\text { entered as a categorical variable in which categorized into four age groups }<20 ; 20-29 ; 30-39 ; \geq 40 \text { yrs. }\end{array}$ \\
\hline Maternal education & $\begin{array}{l}\text { Variable was constructed from two variables; } 1 \text { st is ever attended school. Women who answered "yes" were } \\
\text { asked the second about the highest level she completed. Women who reported that they only completed } \\
\text { the preschool were considered as illiterate and added to women who reported in the first question that they } \\
\text { have never attended school. Women who attended informal education such as "illiterate eradication classes" } \\
\text { are considered in the primary level and then they were added to the women who reported that they } \\
\text { attended primary or intermediate levels (the basic education) Women who reported that they attended } \\
\text { secondary or university levels were grouped together to be the third group. Categories were; illiterate, } \\
\text { intermediate or less ( } \leq 8 \text { years) and secondary or above ( }>8 \text { years) }\end{array}$ \\
\hline Area of residence & Rural/ urban \\
\hline Household head education & $\begin{array}{l}\text { Because of the very high percentage of missing in the education level variable, only ever vs. never had some } \\
\text { education variable has been entered to the analysis as an indicator that lead us to know the role of } \\
\text { education of head of household in any health decision taken. Illiterate / some education. }\end{array}$ \\
\hline Household wealth index & $\begin{array}{l}\text { The original variables has } 5 \text { categories ranged from poorest (the } 1 \text { st quintile) to richest (the } 5 \text { th quintile). } \\
\text { Because of the very small numbers of neonatal deaths in the second and forth quintiles, the } 2 \text { nd and the } 1 \text { st } \\
\text { quintiles were grouped together as well as the } 4 \text { th and the } 5 \text { th quintiles were grouped together. Therefore, } \\
\text { the wealth index that used in the analysis contains three categories: poor, middle, and rich. }\end{array}$ \\
\hline Parity & $\begin{array}{l}\text { The original variable was continuous it was group in to three categories; primiparae, } 2-4 \text { children and } \\
\text { multiparae } \geq 5 \text {. }\end{array}$ \\
\hline $\begin{array}{l}\text { Antenatal care utilization and delivery } \\
\text { assistance }\end{array}$ & $\begin{array}{l}\text { Were constructed from a multiple } 9 \text { alternative health providers. Women who answered: Traditional birth } \\
\text { attendant or Community health worker, no one was coded as non / traditional health providers (THP) users. } \\
\text { whereas women who answered doctor or nurse or village midwife or health visitor or medical assistant were } \\
\text { coded professional health providers (PHP) users. However, if women mentioned that they visited both health } \\
\text { provider belongs to THP group and one belongs to PHP group, they were considered as PHP users. }\end{array}$ \\
\hline Ever had tetanus toxoid vaccination & Yes / No \\
\hline Mode of delivery & $\begin{array}{l}\text { The original variable has three categories: vaginal, Caesarean section, forceps extractor. Because of the very } \\
\text { few cases in the forceps extractor, they were added to vaginal cases. Thus the variable that use in the analysis } \\
\text { includes vaginal and Caesarean section }\end{array}$ \\
\hline Place of delivery & Home/ health facility \\
\hline $\begin{array}{l}\text { Pregnancy complication and delivery } \\
\text { complications }\end{array}$ & $\begin{array}{l}\text { Women were asked about their personal experience in their last pregnancy and last delivery. The variables } \\
\text { were constructed from the responses of the: excessive vaginal bleeding, high blood pressure, convulsions, } \\
\text { high fever, foul smelling vaginal discharge, and Jaundice in which women who reported yes in at least one } \\
\text { of these complications during pregnancy period / delivery were coded } 1 \text { "yes" whereas women who reported } \\
\text { that did not experienced any of these complications were coded } 0 \text { "No". }\end{array}$ \\
\hline
\end{tabular}

\section{Ethics}

Ethical permission for the study was obtained from the Federal Ministry of Health Ethical Committee, Khartoum, Sudan.

\section{Statistical analyses}

First, descriptive analysis using frequency tabulation was conducted. Crude odds ratios and 95\% confidence intervals were calculated to assess the rough effect of each explanatory variable on the neonatal mortality rate without adjusting for other variables. Variables found to be significantly associated with neonatal mortality on at least one category (defined as a p value $<0.05$ ) were entered into a multivariate logistic regression model to evaluate neonatal mortality as a function of demographic, socioeconomic and maternal health indicators. Pregnancy complications were removed from the final model because it was highly correlated to delivery complications. Similarly, parity was removed from the final model because it was highly correlated to maternal age. The final model included maternal age, household wealth index, sex of child, mode of delivery and delivery complications.

The statistical analyses were performed using SPSS ${ }^{\circledR}$ version 18 for Windows (SPSS Inc., Chicago, IL, USA).

\section{Results}

In total, 21,942 women were interviewed, and of the 6,198 live-born children who were included in the analysis, 189 (3.0\%) had died during the neonatal period. Characteristics of the study population are presented in Tables 2 and 3. Approximately $51 \%$ of the children were male, $52 \%$ of the children were born to a mother in the 20-29 years age group, 73\% were born to mothers who lived in rural areas, $45 \%$ were born to mothers who were illiterate $49 \%$ of the heads of the household were 
Table 2 Details of births and neonatal deaths recorded in the Sudan household health survey 2 nd round, 2010 $(\mathrm{N}=6,198)$

\begin{tabular}{|c|c|c|c|}
\hline Characteristics & Number of children & $\%$ & Neonatal mortality rate (per 1000 live births ) \\
\hline \multicolumn{4}{|l|}{ Child sex } \\
\hline Male & 3152 & 50.9 & 38 \\
\hline Female & 3046 & 49.1 & 22 \\
\hline \multicolumn{4}{|l|}{ Maternal age in years } \\
\hline$<20$ & 458 & 7.4 & 26 \\
\hline $20-29$ & 3217 & 51.9 & 30 \\
\hline $30-39$ & 2075 & 33.5 & 26 \\
\hline$\geq 40$ & 448 & 7.2 & 60 \\
\hline \multicolumn{4}{|l|}{ Maternal education } \\
\hline Illiterate & 2803 & 45.2 & 34 \\
\hline Intermediate or less( $\leq 8$ years) & 2366 & 38.2 & 28 \\
\hline Secondary or above (> 8 years) & 1029 & 16.6 & 27 \\
\hline \multicolumn{4}{|l|}{ Area of residence } \\
\hline Urban & 1674 & 27.0 & 31 \\
\hline Rural & 4524 & 73.0 & 31 \\
\hline \multicolumn{4}{|l|}{ Household head education } \\
\hline Illiterate & 3020 & 48.7 & 32 \\
\hline Have some education & 3140 & 50.7 & 28 \\
\hline missing & 38 & 0.6 & \\
\hline \multicolumn{4}{|l|}{ Household wealth index } \\
\hline Lowest & 2860 & 46.1 & 37 \\
\hline Middle & 1366 & 22.0 & 26 \\
\hline Highest & 1972 & 31.8 & 24 \\
\hline
\end{tabular}

illiterate and $46 \%$ of the children were born into poor families (lowest wealth index).

Eighteen per cent of the mothers were primiparae, $74 \%$ of the mothers received professional antenatal care, $70 \%$ had received at least one dose of anti-tetanus vaccine, $92 \%$ of the deliveries were vaginal, $78 \%$ delivered at home, $72 \%$ had professional assistance during delivery, $46 \%$ experienced complications during pregnancy and $36 \%$ experienced complications during delivery.

\section{Crude odds ratios}

Factors significantly associated with neonatal mortality were: older maternal age ( $\geq 40$ years), OR 2.3 compared with age $<20$ years, (95\% CI: 1.16, 4.55, p = 0.017), primiparity OR 2.3, compared with having 2-4 children, (95\% CI: 1.61, 3.23, p < 0.001), lowest household wealth index OR 1.6 compared with highest wealth index, (95\% CI: $1.11,2.21, \mathrm{p}=0.012)$, child of male sex OR $1.6(95 \%$ CI: $1.30,2.38, \mathrm{p}=0.017)$. Pregnancy and delivery complications had a significant association with neonatal mortality (pregnancy complications OR 1.7, (95\% CI: 1.24, 2.23, $\mathrm{p}=0.001$; delivery complications OR 1.4 (95\% CI: 1.06, $1.90, \mathrm{p}=0.018)$. Babies born by Caesarean section were more likely to die before age 28 days than babies born by vaginal delivery OR 1.6 (95\% CI: 0.98, 2.60, p=0.06).

Maternal education, place of residence and the level of education of the head of the household were not significantly associated with neonatal mortality. In addition no significant associations were found with the other maternal health factors: use of antenatal care, tetanus vaccination, assisted delivery or place of delivery, Table 4.

\section{Adjusted odds ratios}

In the multivariate analysis, the risk of neonatal mortality increased significantly with advanced maternal age OR 2.4 (95\% CI: 1.21, 4.78, p = 0.012) for women in age group $\geq 40$ years, compared with women $<20$ years. Low household wealth was associated with increased odds of neonatal mortality compared with high household wealth (OR 1.6; 95\% CI: 1.18, 2.47, $\mathrm{p}=0.005$ ). Male babies have 1.8 times higher odds for neonatal mortality than female babies (95\% CI: 1.31, 2.42, p < 0.001). Babies born by Caesarean section have 1.6 higher odds of neonatal mortality than those born by vaginal delivery $(95 \%$ CI: $1.78,2.42, \mathrm{p}=0.013)$. Delivery complications were associated with 1.4 higher odds for neonatal mortality 
Table 3 Maternal characteristics of the babies recorded in the Sudan household health survey 2 nd round, 2010 $(\mathrm{N}=6198)$

\begin{tabular}{|c|c|c|c|}
\hline Characteristics & Number of children & $\%$ & Neonatal mortality rate (per 1000 live births ) \\
\hline \multicolumn{4}{|l|}{ Parity } \\
\hline primiparae & 1129 & 18.2 & 53 \\
\hline 2-4 children & 2988 & 48.2 & 24 \\
\hline Multiparae $\geq 5$ & 2080 & 33.6 & 27 \\
\hline missing & 1 & 0.0 & \\
\hline \multicolumn{4}{|l|}{ Antenatal care utilization } \\
\hline Non/ traditional care & 1605 & 25.9 & 35 \\
\hline Professional health care & 4593 & 74.1 & 29 \\
\hline \multicolumn{4}{|c|}{ Ever has tetanus toxoid vaccination } \\
\hline Yes & 4356 & 70.3 & 31 \\
\hline No & 1842 & 29.7 & 30 \\
\hline \multicolumn{4}{|l|}{ Delivery assistance } \\
\hline Non/ traditional care & 1634 & 26.4 & 35 \\
\hline Professional health care & 4477 & 72.2 & 29 \\
\hline missing & 87 & 1.4 & \\
\hline \multicolumn{4}{|l|}{ Mode of delivery } \\
\hline Vaginal & 5686 & 91.7 & 29 \\
\hline Caesarean section & 406 & 6.6 & 47 \\
\hline missing & 106 & 1.7 & 30 \\
\hline \multicolumn{4}{|l|}{ Place of delivery } \\
\hline Home & 4834 & 78.0 & 30 \\
\hline Health facility & 1263 & 20.4 & 31 \\
\hline missing & 101 & 1.6 & \\
\hline \multicolumn{4}{|l|}{ Pregnancy complications } \\
\hline Yes & 2835 & 45.7 & 39 \\
\hline No & 3363 & 54.3 & 24 \\
\hline \multicolumn{4}{|l|}{ Delivery complications } \\
\hline$\overline{Y e s}$ & 2250 & 36.3 & 37 \\
\hline No & 3948 & 63.7 & 27 \\
\hline
\end{tabular}

compared with those delivered free of complications (95\% CI: 1.18, 2.15, p = 0.002) Table 4.

\section{Discussion}

Analysis of data from the SHHS2, 2010 has revealed that neonatal mortality is associated with male babies, advanced maternal age, family poverty, delivery of baby by Caesarean section and delivery complications. Advanced maternal age has been associated with preterm delivery and antepartum complications in another study [13] and further studies have found that delivery complications were determinant of poor perinatal outcomes [14,15]. Obstetric complications, particularly in labour, have been reported as risk factors for stillbirths and early neonatal deaths $[6,16]$ and poverty and delivery complications have also been identified as risk factors for neonatal death [7].
In the current study, maternal education was not associated with neonatal mortality, which is in contrast with another study which has found maternal education to be an important determinant of maternal and perinatal outcomes [17]. This may be due to mothers with higher levels of education using more antenatal care [18], however, in Sudan, this may not be the case, as women have no authority in the decision to seek medical care, even if they are educated.

The current study showed that primiparity was associated with neonatal mortality. In contrast, multiparity $(\geq 5)$ has been reported as a risk factor for neonatal mortality [3]. Another result from the current study was the high neonatal mortality risk associated with babies born by Caesarean section. Most Caesarean section may be emergency sections following prolonged attempted vaginal deliveries. 
Table 4 Crude and adjusted odds ratios for factors associated with neonatal mortality

\begin{tabular}{|c|c|c|c|c|}
\hline Factor & Crude OR $(95 \% \mathrm{Cl})$ & $P$ value & Adjusted OR $(95 \% \mathrm{Cl})$ & $P$ value \\
\hline \multicolumn{5}{|c|}{ Maternal age in years $(n=6301)\left(R^{2}=0.023\right)^{* *}$} \\
\hline$<20$ & 1 & & 1 & \\
\hline $20-29$ & $1.1(0.61,2.00)$ & 0.752 & $1.1(0.60,2.00)$ & 0.758 \\
\hline $30-39$ & $0.9(0.50,1.75)$ & 0.841 & $0.9(0.49,1.72)$ & 0.777 \\
\hline$\geq 40$ & $2.3(1.16,4.55)$ & 0.017 & $2.4(1.21,4.78)$ & 0.012 \\
\hline
\end{tabular}

Maternal education $(n=6301)\left(R^{2}=-0.017\right)^{* *}$

Secondary or above ( $>8$ years)

Intermediate or less ( $\leq 8$ years)

1

Illiterate

$1.0(0.65,1.60)$

0.919

Parity* $(n=6301)\left(R^{2}=0.013\right)^{* *}$

2-4 children

primiparae

$1.2(0.82,1.92)$

0.302

Multiparae $\geq 5$

$2.3(1.61,3.23)$
$<0.00$

Household wealth index $(n=6301)\left(R^{2}=-0.034\right)^{* *}$

Highest

Lowest

0.012

Place of Residence $(n=6301)\left(R^{2}=-0.001\right)^{* *}$

Rural

1

Urban

$1.0(0.74,1.41)$

0.918

Child sex $(n=6301)\left(R^{2}=-0.047\right)^{* *}$

Female

Male

$1.6(1.30,2.38)$

0.017

$1.6(1.18,2.47)$

Household head education $(n=6263)\left(R^{2}=-0.007\right)^{* *}$

Have some education

Illiterate

$1.2(0.86,1.55)$

Antenatal care utilization $(n=6301)\left(R^{2}=-0.016\right)^{* *}$

Professional health care

Non/ traditional care

$1.2(0.89,1.68)$

0.211

Ever has tetanus toxoid vaccination $(n=6301)\left(R^{2}=0.001\right)^{* *}$

Yes

$$
1.0(0.72,1.36) \quad 0.948
$$

Delivery assistance $(n=6217)\left(R^{2}=-0.016\right)^{* *}$

Yes

$\frac{1}{1.0(0.72,1.36)} \quad 0.948$

Mode of delivery $(n=6301)\left(R^{2}=0.024\right)^{* *}$

Vaginal

$1.6(0.98)$

Caesarean section

$1.6(0.98,2.60)$

0.060 1

Place of delivery $(n=6206)\left(R^{2}=0.002\right)^{* *}$

Home

Health facility

1

Pregnancy complications* $(n=6301)\left(R^{2}=0.044\right)^{* *}$

No

Yes $1.7(1.24,2.23)$

0.001

Delivery complications $(n=6301)\left(R^{2}=0.030\right)^{* *}$

\begin{tabular}{llll}
\hline \hline No & 1 & & 1 \\
\hline Yes & $1.4(1.06,1.90)$ & 0.018 & $1.4(1.18,2.15)$ \\
\hline
\end{tabular}

*Excluded from the model because of co linearity. ${ }^{* *}$ for the crude analysis. Nagelkerke $R^{2}$ for the final model $=0.060$. 
Unexpected findings from the study were the lack of association between neonatal mortality and the use of antenatal health care services, whether the delivery was assisted by a health care professional or not and whether the birth was at home or in a hospital. A Previous study reported that lack of antenatal care was associated with a higher risk of neonatal mortality [19], and a lack of antenatal care was reported as a determinant of poor perinatal outcomes in central Sudan [17]. Further studies $[7,20]$ have revealed that the majority of neonatal mortality occurs at home with unskilled birth attendance. These findings may reflect the poor quality service provided by nurses and midwives who are still training as birth assistants [21]. Another explanation for this result may be that in Sudan most deliveries start at home and are referred to health facilities as a result of complications e.g. prolonged labour, intra-partum haemorrhage. Thus, hospital deliveries are more complicated and more likely to have poor outcomes. Further study of the quality of services provided and the referral system for hospitals is needed.

This study also found no association between neonatal mortality and the mother ever receiving a tetanus vaccination. The survey question asked the mothers about ever receiving the vaccination, so was not checking for compliance on a course of vaccination, or recent vaccination and a positive answer was not indicative of full protection against tetanus.

In general, the study identified some risk factors for neonatal mortality that are not easily or readily modifiable. These risk factors may underlie the persistently high neonatal mortality rate seen in Sudan, despite the efforts made to reduce it. Identification of these causes of neonatal death is essential so that evidence-based approaches for reducing neonatal mortality in Sudan can be developed.

The main strength of this study is that SHHS2, 2010 was a nationally representative survey, using standardised methods that achieved high individual (91.4\%) and household (99\%) response rates.

One limitation of this study is that in SHHS2, 2010, maternal health indicators were collected from women on their most recent baby delivered within the 2 years preceding the survey. As a result, neonatal mortalities for children born prior to February 2008 were not included in the analysis. In addition, 189 neonatal deaths is a relatively small sample from which to draw definitive conclusions - a larger sample would have provided more power to detect associations between neonatal death and potential risk factors.

\section{Conclusion}

The analysis of the SHHS2, 2010 data revealed that neonatal mortality is associated with poverty, advanced maternal age, having a male child, having a Caesarean section and having complications during the pregnancy. Public health interventions targeting the reduction of neonatal mortality should adopt a risk-factor-based approach to detect pregnancy complications early and to strengthen the health system to deal with problems adequately.

\section{Competing interests}

The authors have no competing interests to declare.

\section{Authors' contributions}

$A O B$ and $I A$ designed the study. GHI and GAB participated in the survey and statistical analyses. All the authors helped draft and approved the final version of the paper.

\section{Acknowledgements}

The study team acknowledges the Federal Ministry of Health, Sudan and the national team conducting the SHHS2, 2010 for their incredible work in collecting such huge amounts of data. We also appreciate the generous financial support offered by UNICEF for both the SHHS2, 2010 and this indepth analysis.

\section{Author details}

${ }^{1}$ Public Health Institute, Khartoum, Sudan. ${ }^{2}$ School of Health Sciences, City University, London, United Kingdom. ${ }^{3}$ Faculty of Medicine, University of Khartoum, Khartoum, Sudan.

Received: 23 September 2012 Accepted: 26 March 2013

Published: 1 April 2013

\section{References}

1. Countdown to 2015. Building a future for women and children.http://www countdown2015mnch.org/reports-and-articles/2012-report.

2. Black RE, Morris SS, Bryce J: Where and why are 10 million children dying every year? Lancet 2003, 361(9376):2226-2234.

3. Titaley C, Dibley M, Agho K, Roberts C, Hall J: Determinants of neonatal mortality in Indonesia. BMC Publ Health 2008, 8(1):232.

4. Bhutta ZA, Chopra M: The Countdown for 2015: what lies ahead? Lancet 2012, 380(9848):1125-1127.

5. Lawn JE, Kinney MV, Black RE, Pitt C, Cousens S, Kerber K, Corbett E, Moran AC, Morrissey CS, Oestergaard MZ: Newborn survival: a multi-country analysis of a decade of change. Health Policy Plan 2012, 27(suppl 3):iii6-iii28.

6. Martines J, Paul VK, Bhutta ZA, Koblinsky M, Soucat A, Walker N, Bahl R, Fogstad H, Costello A: Neonatal survival: a call for action. Lancet 2005, 365(9465):1189-1197.

7. Lawn JE, Cousens S, Zupan J: Lancet Neonatal Survival Steering Team. 4 million neonatal deaths: when? Where? Why? Lancet 2005, 365(9462):891-900.

8. Ollila E: Global health priorities-priorities of the wealthy. Global Health 2005, 1(1):6

9. Knippenberg R, Lawn JE, Darmstadt GL, Begkoyian G, Fogstad H, Walelign N, Paul VK: Systematic scaling up of neonatal care in countries. Lancet 2005, 365(9464):1087-1098.

10. Sudan Household Health Survey 2nd Round 2010 Summary Report July: Federal Ministry of Health, Ministry of Health, Government of South Sudan, Central Bureau of Statistics Southern Sudan Commission of Census, Statistics \& Evaluation. www.unicef.org/about/annualreport/files/Sudan_COAR_2010.pdf.

11. Unicef, Multiple Indicator Cluster Surveys - Round 4. http://www.childinfo.org/ mics4.html.

12. Mosley $\mathrm{WH}$, Chen LC: An analytical framework for the study of child survival in developing countries. Popul Dev Rev 1984, 10:25-45.

13. Seoud MAF, Nassar AH, Usta IM, Melhem Z, Kazma A, Khalil AM: Impact of advanced maternal age on pregnancy outcome. Am J Perinatol 2002, 19(1):1-8.

14. Ali AA, Adam I: Maternal and perinatal outcomes of obstructed labour in Kassala hospital. Sudan. J Obstet Gynaecol 2010, 30(4):376-377.

15. Adam GK, Bakheit KH, Adam I: Maternal and perinatal outcomes of eclampsia in Gadarif Hospital. Sudan. J Obstet Gynaecol 2009, 29(7):619-620.

16. United Nations: The Millennium Development Goals Report. New York: United Nations; 2005. 
17. Hassan AA, Abubaker MS, Radi EA, Adam I: Education, prenatal care, and poor perinatal outcome in Khartoum. Sudan. Int J Gynaecol Obstet 2009, 105(1):66-67.

18. Cleland JG, Van Ginneken JK: Maternal education and child survival in developing countries: The search for pathways of influence. Social Science \&amp; Medicine 1988, 27(12):1357-1368,

19. Nasreen H-E, Bhuiya A, Ahmed SM, Chowdhury M: Woman focused development intervention reduces neonatal mortality in rural Bangladesh: A study of pathways of influence. J Neonatol 2006, 20(4):304-315.

20. Kerber KJ, de Graft-Johnson JE, Bhutta ZA, Okong P, Starrs A, Lawn JE: Continuum of care for maternal, newborn, and child health: from slogan to service delivery. Lancet 2007, 370(9595):1358-1369.

21. Federal Ministry of Health, Sudan, FMOH: Reproductive health directorate, assessment of VMWs in 5 States. 2006. www.jica.go.jp/english/our_work/ .../tech.../sudan_2010_01.pdf.

doi:10.1186/1471-2458-13-287

Cite this article as: Bashir et al: Neonatal mortality in Sudan: analysis of the Sudan household survey, 2010. BMC Public Health 2013 13:287.

\section{Submit your next manuscript to BioMed Central and take full advantage of:}

- Convenient online submission

- Thorough peer review

- No space constraints or color figure charges

- Immediate publication on acceptance

- Inclusion in PubMed, CAS, Scopus and Google Scholar

- Research which is freely available for redistribution 